\title{
Genomic organization and expression of parkin in Drosophila melanogaster
}

\author{
Young-Joo Bae ${ }^{1 *}$, Kwang-Sook Park ${ }^{2 *}$ \\ and Soon-Ja Kang ${ }^{1,3,4}$ \\ ${ }^{1}$ Department of Biological Science \\ College of Natural Science \\ Ewha Womans University, Seoul 120-750 \\ ${ }^{2}$ Department of Microbiology and \\ Institute for Viral Diseases \\ Division of Brain Korea 21 Program \\ for Biomedical Science, College of Medicine \\ Korea University, Seoul 136-705, Korea \\ ${ }^{3}$ Department of Science Education \\ College of Education \\ Ewha Womans University, Seoul 120-750, Korea \\ ${ }^{4}$ Corresponding Author: Tel, 82-2-3277-2690; \\ Fax, 82-2-3277-2684; E-mail, sjkang@ewha.ac.kr \\ *These authors contributed equally to this work. \\ Accepted 22 September 2003
}

Abbreviations: ARJP, autosomal recessive juvenile parkinsonism; $P D$, parkinson's disease

\begin{abstract}
We report here the isolation, characterization on genomic structure and expression of the $D$. melanogaster homolog of human parkin. The 2,122 bp parkin gene sequence contains six exons that form a $1,449 \mathrm{bp}$ transcript encoding a protein of 482 amino acids. $151 \mathrm{bp}$ of $5^{\prime}$ and $112 \mathrm{bp}$ of $3^{\prime}$ untranslated regions were identified by a combination of 5'-RACE/primer extension and 3'-RACE, respectively. The $5^{\prime}$ UTR contains three transcription initiation sites. Neither a classical TATA nor a CAAT box was found in the putative promoter sequence. However, binding sites for AhR-Arnt, AP4, NF1 and GATA transcription factors were identified. Transient transfection analys is of the $5^{\prime}$ UTR confirmed its promoter activity in HEK 293 cells and SH-SY5Y neuronal cells using a dual luciferase reporting system. The amino acid sequence of $D$. melanogaster Parkin exhibits $42 \%$, $43 \%$ and $43 \%$ identity to that of human, mouse and rat, respectively, representing a $54 \mathrm{kDa}$ protein band via western blot analysis. It shows a high degree of conservation in the Ubiquitin-like domain at the $\mathrm{N}$-terminus $(34 \%)$, the In-Between
\end{abstract}

RING finger domains (IBR, 65-69\%), and the RING finger domains at the C-terminus (56-57\%). The expression pattern of $D$. melanogaster parkin varies during the developmental stages, with the highest expression in the adult stage as measured by competitive RT-PCR. From immunostainings of the embryo, D. melanogaster parkin was expressed slightly higher in the central nervous system (brain and nerve cord) during the late embryonic stage.

Keywords: ARJP; Drosophila melanogaster; parkin; Parkinson's disease; Ubiquitin-ligating enzyme

\section{Introduction}

Parkinson's disease (PD, MIM 168600) is a common neurodegenerative disease which has a worldwide distribution and a characteristic movement disorder called parkinsonism in an aged population. The overall prevalence of Parkinson's is $1: 1,000$, but the incidence increases to $1.4 \%$ among individuals 55 years or older and to $3.4 \%$ among individuals age 75 or older (De Rijk et al., 1997). The disease is caused by striatal deficiency of dopamine which primarily results from neuronal death in the substantia nigra (Olanow and Tatton, 1999).

Most cases of PD occur sporadically as an idiopathic form, but there are also hereditary forms. One of which, autosomal recessive juvenile parkinsonism (ARJP), is a clinically distinct entity characterized by typical PD features but with an earlier ( $<40$ years) age of onset. Other characteristics include the presence of foot dystonia, a benefit from sleep, a marked response to L-dopa therapy and the absence of Lewy bodies at autopsy (Yamamura et al., 1973; Takahashi et al., 1994; Forno, 1996; Ishikawa and Tsuji, 1996; Mori et al., 1998). Some families with ARJP have allowed genetic mapping and chromosomal localization of candidate regions for the disease (Polymeropoulos et al., 1996; 1997; Matsumine et al., 1997). Among the genes implicated in familial PD, the largest number of mutations have been found in parkin (gene locus PARK2, MIM 602544), which has been mapped to human chromosome 6q25-27 (Matsumine et al., 1997). Parkin has moderate similarities to ubiquitin at the amino terminus as well as a RING finger motif at the carboxyl terminus. Although Lewy bodies have not been identified in the brain of ARJP 
patients, antibody staining against Parkin or ubiquitin may still reveal sites of protein aggregation at the microscopic level (Hattori et al., 1998b; Kitada et al., 1998; Lcking et al., 2000).

Human parkin consists of 12 exons spanning over $1.5 \mathrm{Mb}$ in length and encodes a $52 \mathrm{kDa}$ protein of 465 amino acids (Hattori et al., 1998a; b; Kitada et al., 1998; Abass et al., 1999). A major transcript of $4.5 \mathrm{~Kb}$ was detected in a wide variety of human tissues (Kitada et al., 1998). Subsequent studies have demonstrated that parkin is expressed in certain neuronal cells of the central nervous system in vivo (Horowitz et al.,1999; Huynh et al., 2001) and functions as a ubiquitin-protein ligase in vitro (Imai et al., 2000; 2001; Shimura et al., 2000), implying that Parkin suppresses neuronal cell degeneration by ubiquitinating misfolded proteins as an E3 enzyme. The expression of parkin in bovine peripheral nerve was investigated by RT-PCR and immunoblot analysis. These results point to diverse roles of parkin not only in the central but also in the peripheral nervous system (Asako et al., 2002).

The mouse cDNA is homologous to human parkin which contains a 1,392 bp open reading frame encoding a 464 amino acid ( $\sim 55 \mathrm{kDa}$ protein). The amino acid sequence of mouse Parkin exhibits $83.2 \%$ identity to human Parkin, including the ubiquitin-like domain at the $\mathrm{N}$-terminus $(89.5 \%$ identity) and the RING finger- like domain at the C-terminus $(90.6 \%)$. Northern blot analysis revealed that the mouse parkin is expressed in various tissues (Kitada et al., 2000). Partial cDNA coding for the rat homolog of parkin has also been isolated and sequenced. The $1.46 \mathrm{~Kb}$ cDNA clone contains a 1,376 bp coding region that also shares strong similarities with human parkin CDNA. RT-PCR and in situ hybridization showed widespread expression of parkin in the rat brain and in the periphery ( $D^{\prime}$ Agata et al., 2000).

Recently, to gain insight into the molecular mechanism responsible for selective cell death in ARJP, Drosophila model was created, indicating that Drosophila parkin null mutants exhibited reduced lifespan, locomotor defects and male sterility with apoptotic muscle degeneration and mitochondrial pathology (Greene et al., 2003). And in Drosophila, Parkin degraded putative $G$ protein-coupled transmembrane polypeptide (Pael-R, Imai et al., 2001) and suppressed its toxicity, which caused age-dependent selective degeneration of Drosophila dopaminergic neurons as a Parkin substrate in the molecular pathway of PD (Yang et al., 2003).

In the light of the involvement of parkin expression levels in ARJP, elucidating the transcription control mechanisms of this gene is of great interest. However, the gene organization and regulatory region have not been well characterized. In this study, the organization and expression of parkin is described in the $D$. melanogaster model system.

\section{Materials and Methods}

\section{D. melanogaster stocks}

Canton-S (Wild type of $D$. melanogaster) strain was kept in a $250 \mathrm{ml}$ glass bottle on a diet of cornmeal, dried yeast, sucrose and agar at $25^{\circ} \mathrm{C}$ and in $60 \%$ relative humidity. Adult flies, pupae, larvae and embryos were harvested and stored at $-70^{\circ} \mathrm{C}$ until use.

\section{Cloning and sequencing of $D$. melanogaster parkin genomic and cDNA}

D. melanogaster parkin genomic and CDNA were amplified by PCR and RT-PCR, respectively, using two primers based on the alignment between Drosophila genome database and the parkin sequences previously reported in human, mouse, rat and bovine [Genbank Accession Numbers: AB009973, AB019558, NM_020093 and AB060701, respectively]: P1, 5'TATAACAAATGAGTTTTATTTT-3' (forward primer) and P2, 5'-TGTACAACGATGACGAAGGAT-3' (reverse primer) as shown in Figure 1. The PCR reaction was performed as follows, $95^{\circ} \mathrm{C}$ for $1 \mathrm{~min} 30 \mathrm{~s}$ and then 40 cycles of $95^{\circ} \mathrm{C}$ for $1 \mathrm{~min}, 50^{\circ} \mathrm{C}$ for $1 \min 30 \mathrm{~s}$, $72^{\circ} \mathrm{C}$ for $1 \mathrm{~min} 30 \mathrm{~s}$ and $72^{\circ} \mathrm{C}$ for $10 \mathrm{~min}$, using $\mathrm{Taq}$ DNA polymerase (Promega) in a final volume of 50 $\mu$ l. The PCR products were purified using the Wizard PCR Prep purification system (Promega), ligated into the PGEM-T easy vector (Promega), and transformed into E. coli competent cells, JM109 (Promega). The parkin clones were confirmed by Colony-PCR and sequenced. For automatic sequencing, the BigDye ${ }^{T M}$ Terminator Cycle Sequencing Ready Reaction Kit (Perkin Elmer) was used according to the manufacturer's instruction on the ABI PRISMTM 377 DNA sequencer (Applied Biosystems). Nucleotide and amino acid sequences of $D$. melanogaster parkin were aligned with that of human, mouse and rat using the Clustal W program and deposited into GenBank. The amino acid sequence of $D$. melanogaster parkin was scanned for functional motifs using ScanProsit (http: //www.us.expasy.org/tools/scanprosite).

\section{3' rapid amplification of CDNA ends (RACE)}

3' RACE was performed using the 3' RACE system for Rapid Amplification of cDNA Ends (Invitrogen). The first strand of cDNA was synthesized with a (3'-) adaptor primer (included in the kit) and amplified with AUAP (in the kit) and P5 primer as shown in Figure 1. To increase the specificity in the amplification reaction, a secondary nested PCR was performed 
with the nested gene specific primer P4 instead of the gene specific primer P5 (Figure 1). Purified products were sequenced as above and the sequence was deposited into GenBank.

\section{5' RACE and primer extension}

To characterize the $5^{\prime}$ UTR of $D$. melanogaster parkin, 5' RACE was performed according to the manufacturer's instructions of the 5' RACE system for Rapid Amplification of cDNA End (Invitrogen). Briefly, poly(A) RNA was reverse transcribed with primer P6 (Figure 1) and the cDNA was $d C$-tailed with terminal deoxynucleotidyl transferase and amplified by PCR using primer AAP (in the kit) and $P 6$ as described above. Furthermore, nested PCR was performed to refine these PCR products with primers AUAP and PE (Figure 1). Purified products were directly sequenced and deposited into GenBank. The identification of putative binding sites was performed using the MATINSPECTOR software (Quandt et al., 1995). To determine the transcription initiation site of $D$. melanogaster parkin, primer extension analysis was also performed using the Primer Extension System (Promega, Yun et al., 2001). The reverse primer PE was labeled with $\left(\gamma^{33} \mathrm{P}\right)$ ATP $(3,000 \mathrm{Ci} / \mathrm{nmol}$, Amersham), hybridized with RNA and extended by AMV reverse transcriptase. The DNA-RNA duplex was analyzed on $8 \%$ denaturing polyacrylamide gel and autoradiographed.

\section{Luciferase assay}

Three constructs, relative to the transcription initiation sites of the $D$. melanogaster parkin gene, were amplified from 5' RACE PCR products containing parkin exon 1, using primers (Figure 1) with Kpn I and Hind III internal restriction sites for cloning. A series of overlapping promoter fragments were digested with Kpn I and Hind III, purified and cloned into the enzyme sites of pGL3-Basic vector (Promega) dephosphorylated (CIAP, Promega). The sequences of these constructs were confirmed by DNA sequencing. The pGL3-Basic vector without insert was also used as a control in the luciferase assay.

FuGene6 (Roche)-mediated transfection of Human embryonic kidney cell (HEK293) and SH- SY5Y neuronal cell were performed as described previously (Jang and Juhnn, 2001; West et al., 2001; 2002). Luciferase-containing constructs were cotransfected with pRL-TK vector (Promega) as a control for transfection efficiency, in a molar ratio of 1:100 (pRLTK vs pGL3). Two days after transfection, cells were rinsed and harvested with Passive Lysis Buffer (Promega). Activities of the firefly luciferase and Renilla luciferase in the cell lysate were measured sequentially using the Dual Luciferase System (Promega) with a luminometer essentially according to the manu- facturer's instructions (Luminoskan TL Plus Luminometer, Bio-Rad). Data were expressed as mean $\pm S D$ of values from three independent experiments.

\section{Competitive RT-PCR}

To compare the relative expression level of $D$. melanogaster parkin amongst different developmental stages, competitive RT-PCR was performed using rp49 as the internal control. Embryo, larva, pupa and adult Canton $S$ were prepared as described above. cDNA was synthesized with oligo (dT) primer (Invitrogen) and amplified by PCR as follows, $95^{\circ} \mathrm{C}$ for $5 \mathrm{~min}$ and then 25 cycles of $95^{\circ} \mathrm{C}$ for $1 \mathrm{~min}, 60^{\circ} \mathrm{C}$ for $1 \mathrm{~min}$ $30 \mathrm{~s}, 72^{\circ} \mathrm{C}$ for $1 \mathrm{~min}$ and $72^{\circ} \mathrm{C}$ for $10 \mathrm{~min}$, using $r p 49$ primers (GenBank Accession Number U92431, nucleotides 43-62 for forward/436-455 for reverse) as the control and P2 and P3 primer (Figure 1) for parkin.

\section{Immunostaining of $D$. melanogaster embryo}

Eggs laid by adult flies were collected on media made of agar, grape juice, methyl 4-hydroxybenzoate and dextrose at $25^{\circ} \mathrm{C}$. Embryo stage was determined according to the standards of Campos-Ortega and Hartenstein (1985). After the chorion and vitelline membranes of the eggs were removed, fixed, and stained with rabbit anti-Pakin polyclonal antibody (AB5112, Chemicon) according to the manufacturer's instructions for the VECTASTAIN ABC Kit (Vector Laboratories).

\section{Expression plasmid construction and immunoblot analysis}

Full length parkin cDNA was ligated into prokaryote expression vector pET-30a (+) (Novagen) and the correct insertion was confirmed by Colony- PCR. After transforming the vector into BL21 competent cells (Novagen), IPTG induction was performed for the expression of Parkin. The IPTG-induced Parkin was separated by SDS-PAGE and transferred to PVDF membrane (Millipore) using mini Trans-Blot Electrophoretic Transfer Cell (Bio-Rad). The membrane was blocked with $5 \%(\mathrm{w} / \mathrm{v})$ nonfat dry-milk and incubated with rabbit anti-Parkin polyclonal antibody (AB5112, Chemicon). Parkin was detected using Western Lighting $^{\mathrm{TM}}$ Chemiluminescence Reagent Plus (PerkinElmer), with anti-rabbit IgG antibodies conjugated with horseradish peroxidase.

\section{Results and Discussion}

\section{Isolation of parkin in $D$. melanogaster}

Genomic DNA and cDNA clones of D. melanogaster parkin were isolated and sequenced. The 2,122 bp 


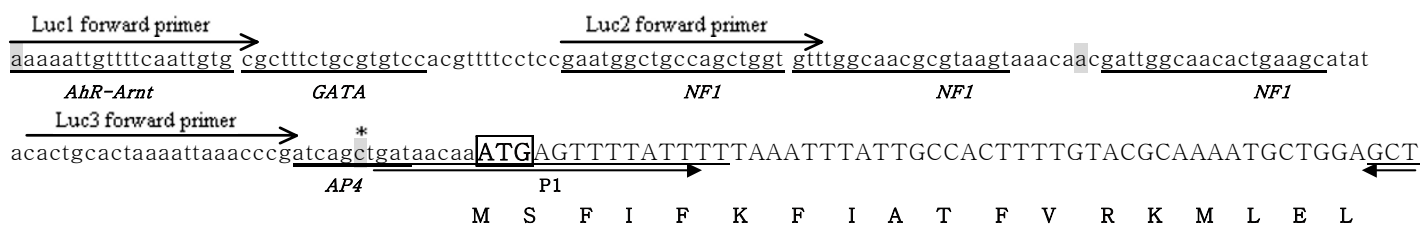

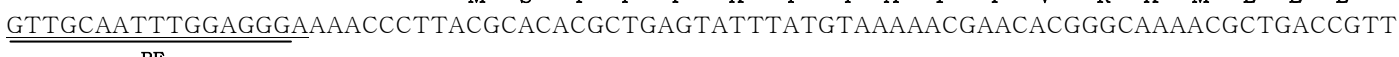

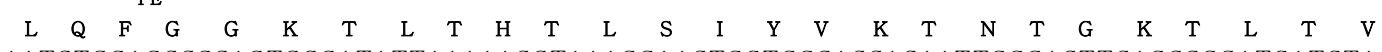
AATCTGGAGCCCCAGTGGGATATTAAAAACGTAAAGGAACTGGTGGCACCACAATTGGGACTTCAGCCGGATGATCTAA

$\begin{array}{lllllllllllllllllllllllllllll}\mathrm{N} & \mathrm{L} & \mathrm{E} & \mathrm{P} & \mathrm{Q} & \mathrm{W} & \mathrm{D} & \mathrm{I} & \mathrm{K} & \mathrm{N} & \mathrm{V} & \mathrm{K} & \mathrm{E} & \mathrm{L} & \mathrm{V} & \mathrm{A} & \mathrm{P} & \mathrm{Q} & \mathrm{L} & \mathrm{G} & \mathrm{L} & \mathrm{Q} & \mathrm{P} & \mathrm{D} & \mathrm{D} & \mathrm{L}\end{array}$ AGATCATATTTGCCGGTAAGGAACTAAGCGATGCCACGACAATAGAGgtaagaagtttctttaatgtatccgctacatgaagttaacttttactgt $\begin{array}{llllllllllllllllllllll}\mathrm{K} & \mathrm{I} & \mathrm{I} & \mathrm{F} & \mathrm{A} & \mathrm{G} & \mathrm{K} & \mathrm{E} & \mathrm{L} & \mathrm{S} & \mathrm{D} & \mathrm{A} & \mathrm{T} & \mathrm{T} & \mathrm{I} & \mathrm{E}\end{array}$ cttctagtagCAATGTGACTTGGGTCAGCAAAGCGTTTTGCATGCCATTCGTTTGCGACCGCCCGTGCAGCGCCAGAAAATCC $\begin{array}{llllllllllllllllllllllllll}Q & C & D & \text { L } & G & Q & Q & \text { S } & \text { V } & \text { L } & \text { H } & \text { A } & \text { I } & \text { R } & \text { L } & \text { R } & \text { P } & \text { P } & \text { V } & \text { Q } & \text { R } & \text { Q } & \text { K } & \text { I }\end{array}$ AGTCGGCCACTTTGGAGGAGGAGGAACCTTCGCTTAGCGATGAAGCCTCCAAGCCTCTAAATGAAACTCTGTTGGACTT $\begin{array}{lllllllllllllllllllllllllllllllllll}\mathrm{Q} & \mathrm{S} & \mathrm{A} & \mathrm{T} & \mathrm{L} & \mathrm{E} & \mathrm{E} & \mathrm{E} & \mathrm{E} & \mathrm{P} & \mathrm{S} & \mathrm{L} & \mathrm{S} & \mathrm{D} & \mathrm{E} & \mathrm{A} & \mathrm{S} & \mathrm{K} & \mathrm{P} & \mathrm{L} & \mathrm{N} & \mathrm{E} & \mathrm{T} & \mathrm{L} & \mathrm{L} & \mathrm{D}\end{array}$ GCAGCTGGAAAGCGAGGAGCGTCTGAATATAACCGATGAAGgtaggcaacaattagtttttattgtttttttttttttaacgaaaccccttgtaatccc $\begin{array}{llllllllllllllllllllll} & \mathrm{Q} & \mathrm{Q} & \mathrm{L} & \mathrm{E} & \mathrm{S} & \mathrm{E} & \mathrm{E} & \mathrm{R} & \mathrm{L} & \mathrm{N} & \mathrm{I} & \mathrm{T} & \mathrm{D} & \mathrm{E}\end{array}$ gtcgtatcctctccagAAAGAGTCCGTGCCAAAGCGCATTTCTTTGTACATTGCAGCCAATGCGATAAGCTGTGTAATGGCAAAC

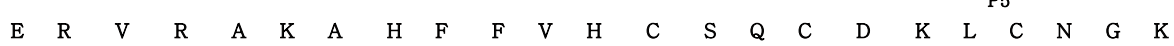
TTCGGGTCCGCTGCGCTTTATGCAAGGGCGGCGCCTTTACTGTCCATCGTGATCCGGAGTGTTGGGATGATGTCTTGAA $\begin{array}{llllllllllllllllllllllllllllllll}\mathrm{L} & \mathrm{R} & \mathrm{V} & \mathrm{R} & \mathrm{C} & \mathrm{A} & \mathrm{L} & \mathrm{C} & \mathrm{K} & \mathrm{G} & \mathrm{G} & \mathrm{A} & \mathrm{F} & \mathrm{T} & \mathrm{V} & \mathrm{H} & \mathrm{R} & \mathrm{D} & \mathrm{P} & \mathrm{E} & \mathrm{C} & \mathrm{W} & \mathrm{D} & \mathrm{D} & \mathrm{V} & \mathrm{L} & \mathrm{K} \\ \end{array}$

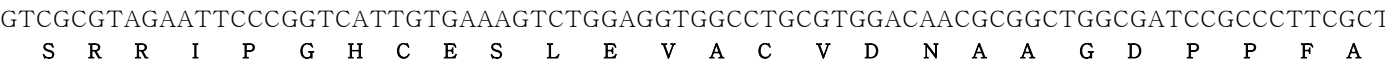
GAATTCTTCTTCAAGTGTGCTGAGCATGTCTCCGGCGGGGAGAAGGATTTTGCGGCTCCATTGAATCTAATCAAGAATAA

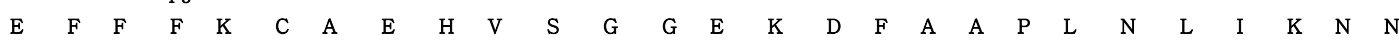
CATCAAGAATGTTCCTTGCCTGGCCTGCACGGATGTGAGgtgattatgcaataaggaacatcttaatttcttataattttcatatcatcgaaaatgtcat $\begin{array}{llllllllllllllllllll}I & \mathrm{~K} & \mathrm{~N} & \mathrm{~V} & \mathrm{P} & \mathrm{C} & \mathrm{L} & \mathrm{A} & \mathrm{C} & \mathrm{T} & \mathrm{D} & \mathrm{V} & \mathrm{S}\end{array}$

aaaaagttcttttaaagtctttaaagtaattatttgtcatataattttattctgctataatcaccttattatgttcgcagTGATACCGTGTTGGTTTTCCCCTGCGC

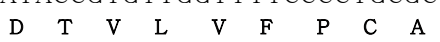
ATCGCAGCACGTCACCTGTATCGACTGCTTCCGCCATTATTGCCGTTCCCGTTTGGGCGAGCGTCAGTTTATGCCGCATC $\begin{array}{llllllllllllllllllllllllllll}\mathrm{S} & \mathrm{Q} & \mathrm{H} & \mathrm{V} & \mathrm{T} & \mathrm{C} & \mathrm{I} & \mathrm{D} & \mathrm{C} & \mathrm{F} & \mathrm{R} & \mathrm{H} & \mathrm{Y} & \mathrm{C} & \mathrm{R} & \mathrm{S} & \mathrm{R} & \mathrm{L} & \mathrm{G} & \mathrm{E} & \mathrm{R} & \mathrm{Q} & \mathrm{F} & \mathrm{M} & \mathrm{P} & \mathrm{H}\end{array}$ CGGACTTCGGCTACACCTTGCCCTGTCCCGCAGGCTGCGAGCACTCGTTCATCGAGGAGATTCATCACTTCAAGCTGTTG

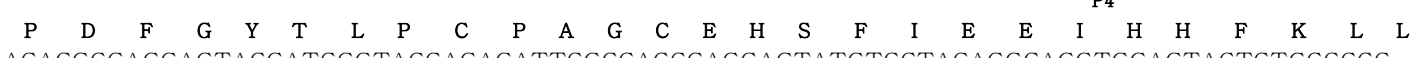
ACACGCGAGGAGTACGATCGGTACCAGAGATTCGCCACCGAGGAGTATGTCCTACAGGCAGGTGGAGTACTCTGCCCCC $\begin{array}{lllllllllllllllllllllllllllllllllll}\mathrm{T} & \mathrm{R} & \mathrm{E} & \mathrm{E} & \mathrm{Y} & \mathrm{D} & \mathrm{R} & \mathrm{Y} & \mathrm{Q} & \mathrm{R} & \mathrm{F} & \mathrm{A} & \mathrm{Y} & \mathrm{E} & \mathrm{E} & \mathrm{Y} & \mathrm{V} & \mathrm{L} & \mathrm{Q} & \mathrm{A} & \mathrm{G} & \mathrm{G} & \mathrm{V} & \mathrm{L} & \mathrm{C} & \mathrm{P}\end{array}$ AGCCAGGATGCGGCATGGGCCTTTTGGTGGAGCCCGATTGTCGCAAGGTGACATGCCAGAACGGCTGTGGATACGTGTT

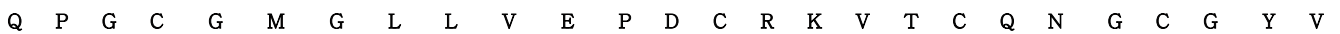
CTGCCGCAATTGTCTGCAGGGCTACCATATCGGGGAGTGTCTGCCCGAGGGGACGGGCGCCAGTGCCACAAACTCCTGC $\begin{array}{llllllllllllllllllllllllllllll}\mathrm{F} & \mathrm{C} & \mathrm{R} & \mathrm{N} & \mathrm{C} & \mathrm{L} & \mathrm{Q} & \mathrm{G} & \mathrm{Y} & \mathrm{H} & \mathrm{I} & \mathrm{G} & \mathrm{E} & \mathrm{C} & \mathrm{L} & \mathrm{P} & \mathrm{E} & \mathrm{G} & \mathrm{T} & \mathrm{G} & \mathrm{A} & \mathrm{S} & \mathrm{A} & \mathrm{T} & \mathrm{N} & \mathrm{S} & \mathrm{C}\end{array}$ GAGTACACCGTGGACCCAAATgtgagttggctcttatacggcccattccegcttgtgtaatcatgtgcttttttagCGAGCTGCCGAGGCGCGATGG

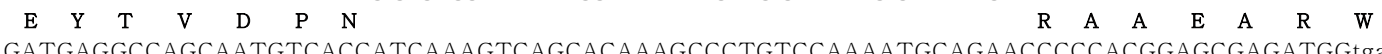

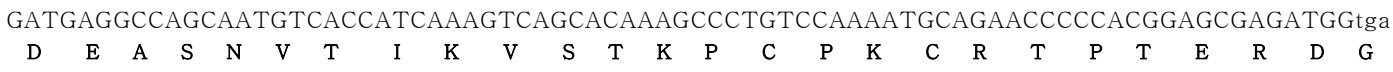
gttgggcgagcatcgaagacacccaagacgcagtttgtaacacatccataccgtcttcttctcttcctaccagGCGGTTGCATGCACATGGTCTGACCACG $\begin{array}{lllllllllllllll}G & C & M & H & M & V & C & T & R\end{array}$

CGCTGGCTGCGGATTCGAGTGGTGCTGGGTCTGCCAGACTGAGTGGACACGCGACTGCATGGGAGCCCACTGGTTCGGC

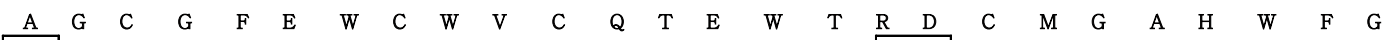
$\underbrace{\text { TAAtccttcgtcatcgttgtacatcggeccgacgggtccttttgtttgttgactacttttaaattgtataccataataaalgactgctcgaacaacaaaaaaaaaaaaaaaa }}_{\mathrm{P} 2}$

aa

Figure 1. Genomic organization of D. melanogaster parkin. Parkin exons are listed in capital letters, while the translation initiation, termination codon and polyadenylation signal are indicated with boxes. Shaded boxes represent transcription initiation sites. The major transcription initiation site, indicated by an asterisk, was designated as the +1 position. The consensus sequences for various transcription factors are shown in italic and underlined. The primers used for the experiments are underlined and denoted with arrows. This sequence was deposited into GenBank (Accession Numbers AF510072, AY093423, AY207374 and AY261675). 


\begin{tabular}{|c|c|}
\hline Human & MIVFVRENSSHGFPVVDSDISIFQLKEVA \\
\hline Mouse & -MIVFVRENSSYGFPVEDSDISII QLKEVWA \\
\hline Rat & - MIVFVRNSSYGFPVVDSDISIFQLUEVA \\
\hline Drosophila & 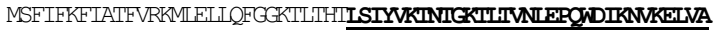 \\
\hline Himan & KRQGVPADQIRVIFAGKEIRNDWIVGNODIDQgSTVHIVGR--FWRKGQFMNATGGDDPR \\
\hline Mouse & 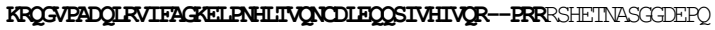 \\
\hline Rat & KRQGVADQIRVIFAGKEIGNHITVGNODIEQQSTVHIVGR--PQRKSHETINASGGDKPQ \\
\hline Drosophila & 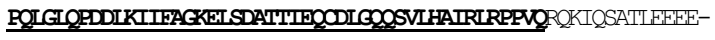 \\
\hline Human & NAAGGCEREPQSLIRVDLSSSVLPGDSVGIAVILHTDSRKDSPPAGSPAGRSIYNSEYVY \\
\hline Mouse & STSEGSIWESRSLTRVDLSSHILPVDSVGLAVILDTDSKRDSEAARG-PVKPTYNSEFIY \\
\hline Rat & STPEGSIWEPRSLTRVDLSSHILPADSVGLAVILDTDSKSDSEAARGPAAKPTYHSEFVY \\
\hline Drosophila & --PSLS-- - - -DEASKPINETLDLQIESEFRLNITDEFR--VR-AKAHFFVH \\
\hline Himan & CKGPCQRVQPGKLRVQCSTCRQATLTLTQGPSCWDDVLIPNRMSGECOSPHCPGIS---- \\
\hline Mouse & CKGPCHKVQPGKLRVQCGTCKQATLTIAQGPSCWDDVLIPNRMSGECQSPDCPGIR---- \\
\hline Rat & CKGPCHKVQPGKLRVQCGTCRQATLITAQGPSCWDDVLIPNRMSGECQSPDCPGIR---- \\
\hline Drosophila & CS-QCDKLCNGKLRVRCALCKGGAFIVHRDPECWDDVLKSRRIPGHCESIEVACVDNAAG \\
\hline Himan & ---AFFFEKCGAHPTS-DKETPVALHLIATNSRNITCIICIDVRSELVECONSRHVIC \\
\hline Mouse & ---AEFFHKCGAHPIS-DKDTSVAINLITSNRRSIPCIACIDVRSEVLVEONHRHIC \\
\hline Rat & --DEFHEKCGAHPTS-DKDISVAINLITNNSRSIFCIACIDVRNEVLVECONHRHC \\
\hline Drosophila & DPPFAFFFHKCAEHVSGGEKDFAAPINLTKNNIKNVPCIACIDVSDIVLVEPCASQHVIC \\
\hline Human & 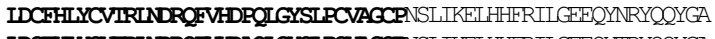 \\
\hline Mouse & IDCEHLYCVIRLNDRQFVEDAQLGYSLPCVAGCPNSL TKEL HHFRILGEEYYTRYQYGA \\
\hline Rat & IDCFHLYCVIRINDRQFVHDAQLGYSTPCVAGCPNSLIKEI HHFRILGEFQYIRYQQYGA \\
\hline Drosophila & IDCFRHYCRSRTGERQFMPHPDFGYTLCPAGCEHSFIFEIHHFKLIREEYDRYQRFAT \\
\hline Human & FECVLIMGGVICPRPGOCAGILPEPDDRKVICEGANGIGCGFAFCRECKEAYHEGECSAV \\
\hline Mouse & FECVLQMGGVICPRPGOCAGLIPEQGQRKVICFGENGIGCGFVECRDCKEAYHEGDCDSL \\
\hline Rat & EECVLQMGGVICPRPGCGAGILPEQGQRKVICFGQNGIGCGFVFCRDCKEAYHEGECDSM \\
\hline Drosophila & 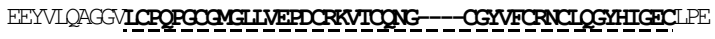 \\
\hline Human & FE-ASGITTQAYRVDERAAEQARWEAASKETIKKTTKPCPRCHVPVENGCOMFMKCPQP \\
\hline Mouse & LE-PSGATSQAYRVDKRAAEQARWEFASKETIKKTTKPCIRONVIFKNGCOMFMKCPQP \\
\hline Rat & FE-ASGATSQAYRVDQRAAEQARWEEASKEITIKKI'TKPCPRONVIEKNGGOMMMCPQP \\
\hline Drosophila & GIGASATNSCEYIVDPNRAAEARWDEASNVTIKVSTKPCPKCRTPIERDGCOMHMCIRA \\
\hline Himan & QCRIEWCWNOGCENARVOMGDHNEDV \\
\hline Mouse & CCKIEWCWNCGCENNRAOMGDHWEDV \\
\hline Rat & QCKIEWCWNCGCENNRAOMGDHWEDV \\
\hline Drosophila & GCGEEWOWOOIEWIRDOMGAHNFG- \\
\hline
\end{tabular}

Figure 2. Alignment of the deduced amino acid sequence of $D$. melanogaster parkin with human, mouse and rat. The sequences previously reported in human, mouse and rat (GenBank Accession Numbers AB009973, AB019558 and NM_020093, respectively) were compared with that of $D$. melanogaster parkin (GenBank Accession Number AY093423). The conserved domains are in bold and ubiquitin-like domain is underlined. RING domains are shown in double underlining and IBR domain is indicated as a dotted line.

gene sequence of parkin is composed of six exons. The 1,478 bp cDNA sequence encodes a protein of 482 amino acids with a calculated molecular weight of $54 \mathrm{kDa}$. The exon-intron boundaries followed the GT-AG rule for intron splicing, except for the boundary after exons 4 (GT/AT) and 5 (GT/TG). Gene structure analysis indicates that the coding sequence of $D$. melanogaster parkin is encoded by six exons, while the human parkin is encoded by twelve exons (Figure 1). The full length of $D$. melanogaster parkin is much shorter in length than that of human because of its strikingly short introns.

The mRNA and gene sequences of $D$. melano- gaster parkin, as deposited in GenBank Accession Numbers AY093423 and AF510072 respectively, was aligned with those of human, mouse and rat (Figure 2). The homology in the nucleotide sequence between D. melanogaster parkin and human, mouse and rat was $34 \%, 33 \%$ and $34 \%$ in each case. When the deduced amino acid sequence was compared, $D$. melanogaster Parkin has a $42 \%$ identity with human, and a $43 \%$ identity with mouse and rat. As shown in Figure 2, D. melanogaster Parkin has a ubiquitinlike domain comprising of 77 amino acid residues (position 30-106) at the N-terminus similar to that of human, mouse and rat. It also contains two $\mathrm{C} 3 \mathrm{HC} 4-$ 
type RING finger domains at the C-terminus and an In-Between RING finger (IBR) domain. RING1, RING2 and IBR domains are located at positions 259-315 (57 residues), 436-476 (41 residues) and 352-394 (43 residues), respectively. IBR, a cysteine-rich domain, has the consensus pattern of $C-x(4)-C-x(14-30)-C-x(1-4)-$ $\mathrm{C}-\mathrm{x}(4)-\mathrm{C}-\mathrm{x}(2)-\mathrm{C}-\mathrm{x}(4)-\mathrm{H}-\mathrm{x}(4)-\mathrm{C}$. The deduced amino acid sequence of the Ubiquitin-like domain showed a $34 \%$ identity when compared with that of human, mouse and rat. The amino acid sequence of the IBR domain has a $69 \%, 65 \%$ and $67 \%$ identity when compared to that of human, mouse and rat, respectively. The amino acid sequence of the RING1 domain has a $57 \%, 56 \%$ and $56 \%$ identity as compared to that of human, mouse and rat, while the RING2 domain has a $56 \%$ identity when compared to that of human, mouse and rat. Such a high degree of conserved homology amongst these different species suggests that these domains are essential for Parkin functions, as previously mentioned by Huynh et al. (2001). The RING-IBR-RING domain arrangement was predicted to regulate gene expression (Morett and Bork, 1999), but it is unlikely that Parkin has a function in the nucleus because Parkin is not localized in the nucleus (Kitada et al., 2000). It is more likely that this domain arrangement in $D$. melanogaster Parkin contributes to the interaction with ubiquitin-conjugating enzymes (E2, UbcH7 and Ubch8) as a ubiquitin-ligating enzyme (E3) in the ubiquitin proteasomal pathway. This is the case in human, mouse and rat (D' Agata et al., 2000; Kitada et al., 2000).

Similar to human, mouse and rat Parkin, D. melanogaster Parkin possesses several consensus sequences of potential phosphorylation sites for protein kinase C (positions 38-40, 201-203, 428-430, 432$434,443-445)$, casein kinase II $(83-86,114-117$, $121-124,133-136,148-151,164-167,237-240,280-$ 283, 317-320, 329-332, 441-444, 443-446) and cAMPand cGMP-dependent protein kinase (369-372). But unlike that of human, mouse and rat, there was no phosphorylation sites for tyrosine kinase found in $D$. melanogaster Parkin (Figure 2).

Using the RACE method, $151 \mathrm{bp}$ of $5^{\prime}$ UTR (GenBank Accession Number AY261675) and 112 bp of 3' UTR (GenBank Accession Number AY207374) were discovered for the $D$. melanogaster parkin cDNA. These UTR sequences were instrumental in identifying the initiation and termination sites of transcription. The 3' RACE generated a 1,097 bp PCR product, while the nested PCR showed a 638 bp product (Figure 3 ). The poly(A) site was located 15 bp downstream of a polyadenylation signal sequence. The results indicate that there is no alternative splicing in the $3^{\prime}$ UTR and that the $1.7 \mathrm{~Kb}$ major transcript was identified as confirmed by Greene et al. (2003).

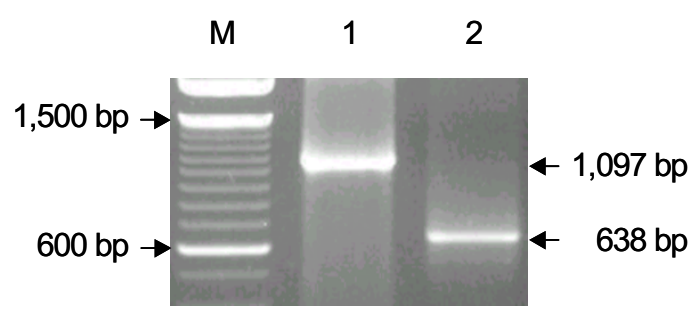

Figure 3. 3' RACE. PCR produced only one product, 1,097 bp in size and nested PCR showed a 638 bp product. The sequence of $3^{\prime}$ UTR in $D$. melanogaster parkin was deposited into GenBank (Accession Number AY207374). Lane M, 100 bp DNA ladder (Invitrogen); lane 1, 3' RACE PCR product; lane 2, Nested PCR product.

\section{Identification of transcription initiation sites}

The transcription initiation site of $D$. melanogaster parkin was determined using a combination of primer extension and 5' RACE. Primer extension analysis was performed using a PE primer positioned at exon 1. The resulting three bands extended the $D$. melanogaster parkin mRNA. But, an 80 bp size product showed was much stronger, indicating a major transcription initiation site (Figure 4B). We performed 5' RACE analysis to ascertain where transcription initiation sites are present (Figure 4A). 445 bp, 356 bp and $304 \mathrm{bp}$ of primary PCR products were obtained and subsequent nested PCR generated $257 \mathrm{bp}, 168$ $\mathrm{bp}$ and $116 \mathrm{bp}$ products. The estimated transcription initiation sites were mapped at $151 \mathrm{bp}, 62 \mathrm{bp}$ and $10 \mathrm{bp}$ upstream of the ATG translation initiation site (Figure 1). The 5'-most initiation site has been designated as the +1 position and corresponds to a cytosine residue at position -10 relative to the ATG initiation codon. Other positions indicated alternative transcription initiation sites and these 5' UTR variants may be generated from the use of alternative promoters. In human parkin, two transcription initiation sites were located at $97 \mathrm{bp}$ and $154 \mathrm{bp}$ upstream of ATG using primer extension as described by West et al. (2001). Like human parkin, consensus TATA and CAAT boxes that could define a transcription initiation site were not found in the putative promoter regions (West et al., 2001). However, the sequences surrounding the three transcription initiation sites contained several sequence elements that were identified by the MATINSPECTOR program (Figure 1). These sequence elements include consensus binding sites for AhR-Arnt, AP4, NF1 and GATA transcription factors that define the transcription initiation site in many TATA-less promoters (Jiang et al., 2000), suggesting that these sites may be functionally involved in the transcriptional control of $D$. melanogaster parkin and in the bi-directional transcription activation within the promoter like human (West et al., 2003). In human, the analysis of parkin promoter identified a novel gene of unknown function, parkin co-regulated gene 
A

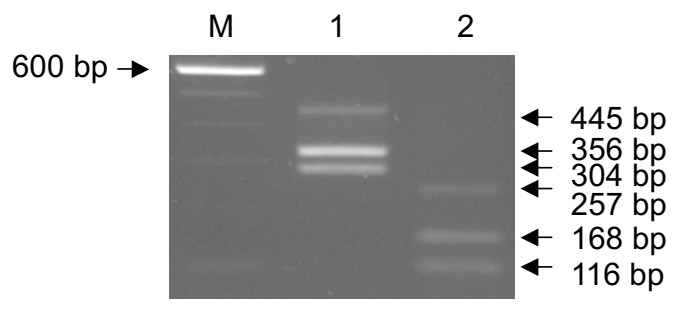

B

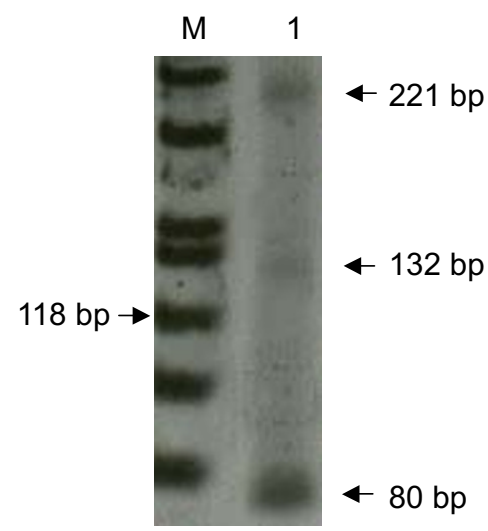

Figure 4. Identification of the transcription initiation sites in $D$. melanogaster parkin. (A) 5' RACE. Amplifications with primers specific for parkin produced 445,356 and 304 bp products (lane 1). A secondary nested PCR showed 257 bp, 168 bp and 116 bp products in size (lane 2). The products were directly sequenced and revealed transcription initiation sites $151 \mathrm{bp}, 62 \mathrm{bp}$ and $10 \mathrm{bp}$ upstream of the parkin translation initiation codon. Lane M, 100 bp DNA ladder (Invitrogen); lane 1, 5' RACE PCR product; lane 2, Nested PCR product. (B) Primer extension. The assay revealed three extension products corresponding with 5' UTR of approximately $221 \mathrm{bp}, 132 \mathrm{bp}$ and 80 bp. Lane M, labeled $\Phi$ X174Hinf I DNA markers; lane 1, extension products of mRNA, which are indicated by arrows.
(PACRG) which shared a common promoter with parkin (West et al., 2003). And based on the highly conserved $D$. melanogaster homolog of PACRG, $D$. melanogaster parkin may interact with $D$. melanogaster PACRG in an uncharacterized biological pathway like human parkin (West et al., 2003). However, it is unclear which of the transcription factors play a role in the transcriptional regulation of $D$. melanogaster parkin under normal or pathological conditions. Therefore, more work needs to be done on the putative role of these transcription factors in regulating parkin expression.

\section{Promoter activity of parkin in D. melanogaster}

To assess whether the 5 '-flanking region of $D$. melanogaster parkin could support transcription in mammalian cell lines, three deletion constructs of the parkin promoter spanning -141 to $+268 \mathrm{bp},-93$ to $+268 \mathrm{bp}$ and -27 to +268 bp were generated by PCR as described by Jiang et al. (2000) and West et al. (2001). The same reverse primer (Luc) for all constructs and various forward primers (Luc1, Luc2 and Luc3) were used (Figure 1). These constructs were fused to the luciferase gene in the pGL3-Basic vector. Transient transfection experiments with vectors containing inserts and empty vectors were performed in HEK293 and SH-SY5Y cells. In three replicate experiments, there was significantly higher promoter activity detected in the pGL3-Basic vectors with promoter region inserts as compared to the those without insert (Figure 5), indicating that there is transcription initiations within these promoter regions. Differences were found in the level of expression

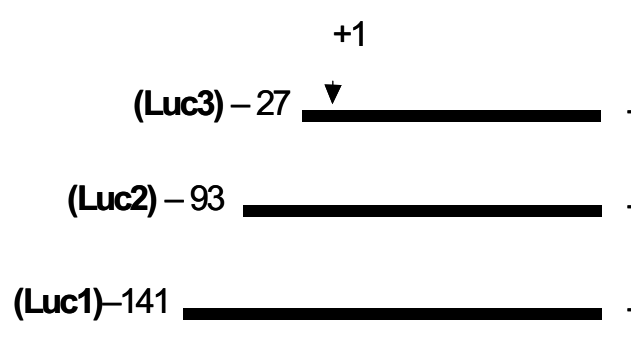

(Empty vector)
$+268$

$+268$

$+268$

\section{Relative luciferase activity} (\% of Empty vector)

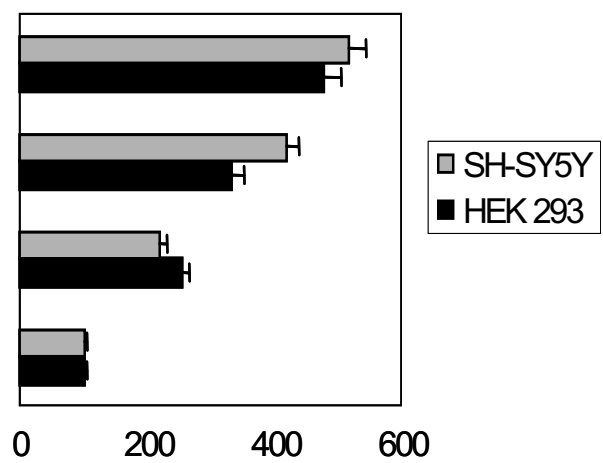

Figure 5. Analysis of the promoter activity of parkin by transient expression. On the left is a depiction of the fragments used for the construction in which three parkin promoter regions were designed and inserted upstream of the luciferase gene; numbers indicated the position on the promoter sequence of the beginning and the end of each fragment. The major transcription initiation site was designated as +1 . Shown on the right are the results obtained by cotransfection of HEK293 (black bar) and SH-SY5Y cells (striped bar) with the corresponding constructs and the control vector. Values of luciferase activity were normalized and represent the mean S.D. of three independent experiments $(n=3$, $P<0.05)$. 
between the cell lines and amongst the constructs. Although the relative luciferase activity was similar within each cell line, the relative activity was higher in SH-SY5Y cells. Interestingly in both cell lines, the promoter construct spanning -27 to $+268 \mathrm{bp}$ revealed a higher promoter activity, while the -27 to $-93 \mathrm{bp}$ and -93 to $-141 \mathrm{bp}$ constructs showed a significantly decreased activity, indicating that some elements in these regions may down-regulate the expression of $D$. melanogaster parkin. These results suggested that the $5^{\prime}$ region of $D$. melanogaster parkin contains regulatory sequences and functions as a promoter of gene transcription. While the regulatory mechanisms controlling $D$. melanogaster parkin transcription are not known, these data represent an important first step in understanding this process.

\section{Expression of D. melanogaster parkin}

Competitive RT-PCR was performed to quantify the relative expression of $D$. melanogaster parkin amongst the different developmental stages. A 788 bp PCR product was amplified using $\mathrm{P} 2$ and $\mathrm{P} 3$ primers, while a $413 \mathrm{bp}$ product of the rp49 gene was co-amplified as an internal control (Figure 6). The results showed that parkin was expressed highest in the adult stage followed by the embryonic, larval and pupal stages in decreasing order. To verify the possibility that the expression of parkin is differentially regulated during development, we investigated the temporal and spatial expression patterns of parkin in Drosophila embryos at different developmental stages as shown in Figure 7. Immunostaining of embryos showed that parkin was expressed across the whole embryo in early stage 2 (Figure 7A). At stage 5, parkin was ex-
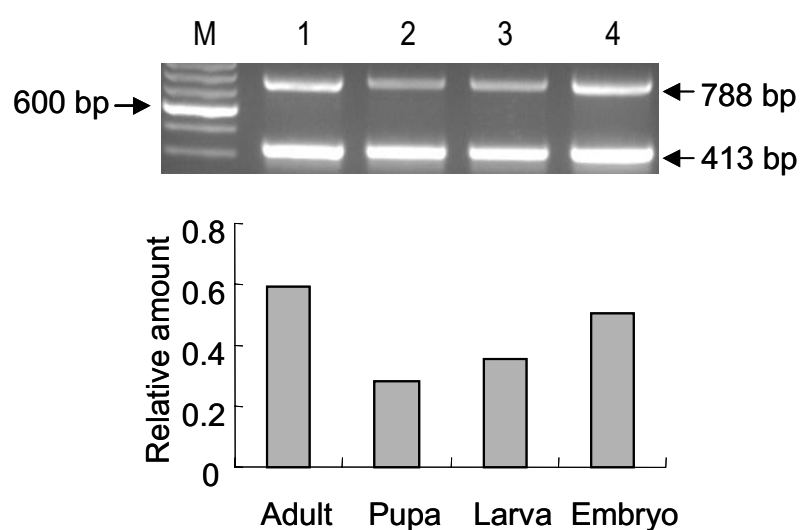

Figure 6. Competitive RT-PCR. Upper and lower bands represent the $788 \mathrm{bp}$ of PCR product for D. melanogaster parkin and the $413 \mathrm{bp}$ of product for rp49 respectively. Lane M, 100 bp DNA ladder (Invitrogen); lane 2, adult; lane 3, pupa; lane 4, larva; lane 5, embryo. pressed evenly across the embryo but at a somewhat lower level (Figure 7B). At stage 8, parkin was expressed higher at the anterior (cephalic furrow) than other parts of the embryo (Figure 7C). Stage 9 showed higher expression of parkin in neuroblast. At stage 10 , the procepalon and dorsal regions showed a higher expression of parkin particularly at the region around the clypeolabrum. At stage 13, parkin showed higher expression in the procephalon and ventral nerve cord regions (Figure 7D). In summary, parkin was expressed ubiquitously and at higher levels in the early stages. The expression level was a whole de-
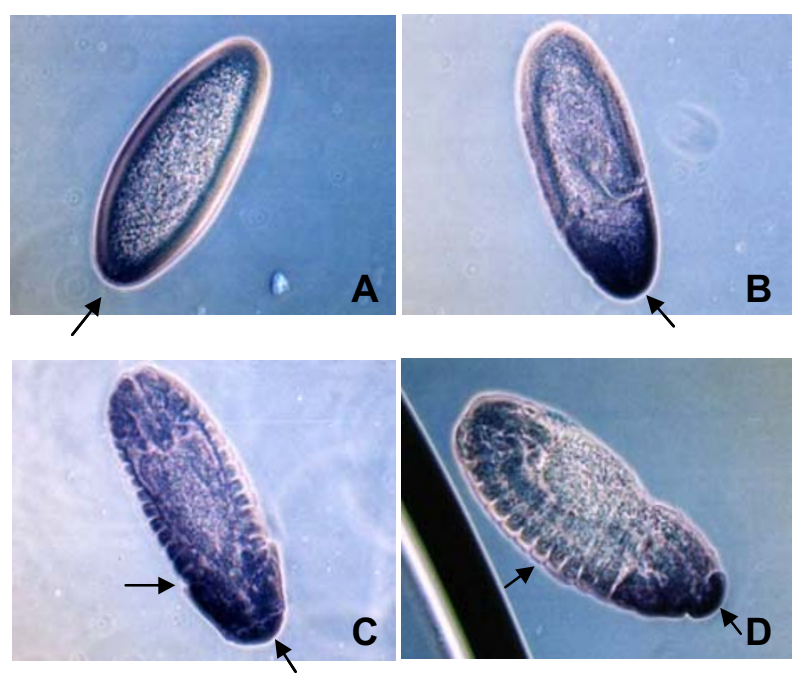

Figure 7. Immunostaining of parkin in D. melanogaster. Temporal and spatial expression patterns of parkin are shown by arrowheads. Embryo was immunostained for Parkin using antibody. (A) embryo at stage $2 ;(B)$ at stage $5 ;(C)$ at stage $8 ;(D)$ at stage 13 . Stage of D. melanogaster embryo was determined by Campos-Ortega and Hartenstein (1985).

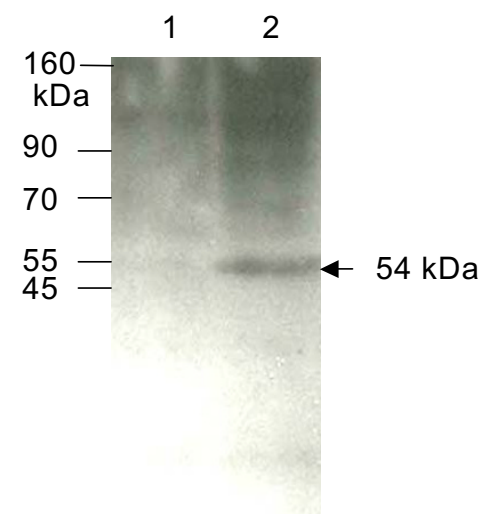

Figure 8. Immunoblot analysis. The IPTG-induced Parkin in E. coli was detected with antibody. As a result, one major protein band (54 $\mathrm{kDa}$ ) which represented the full-length $D$. melanogaster Parkin was identified. Lane 1, without IPTG-induction; lane 2, with IPTG-induction. Molecular weight markers in $\mathrm{kDa}$ are shown on the left. 
creased in the later stages. But, expression was more concentrated at the central nervous system (brain and nerve cord) in the later stages, which is in line with its function in the central nervous system.

And we performed the immunoblot analysis on IPTG-induced Parkin in E. coli using anti-Parkin antibody (Figure 8 ), which showed one prominent band with a molecular weight of $54 \mathrm{kDa}$, as described previously (Horowitz et al., 2001). In Horowitz et al. (2001), Parkin was detected in a diverse set of organisms including $D$. melanogaster, frogs, birds and mouse, indicating that Parkin may play a universal role that has been preserved across different species in evolution. Since D. melanogaster is an efficient model for studying genes in human disease, it will be important to study the effects of parkin mutations as it relates to PD. D. melanogaster gene homolog of human, mouse, rat and bovine genes have yielded invaluable insight into the molecular mechanisms underlying disease and offer exciting possibilities for therapy (Schenk et al., 1999).

\section{Acknowledgement}

This work was supported by a grant R06-2002-01101001-0 (2002) from the Korean Science and Engineering Foundation.

\section{References}

Abass N, Lcking CB, Ricard S, Drr A, Bonifati V, De Michele G, Bouley S, Vaughan JR, Gasser T, Marconi R, Broussolle E, Brefel-Courbon C, Harhangi BS, Oostra BA, Fabrizio E, Bohme GA, Pradier L, Wood NW, Filla A, Meco G, Denefle $P$, Agid $Y$, Brice A. A wide variety of mutations in the parkin gene are responsible for autosomal recessive parkinsonism in Europe. Hum Mol Genet 1999;8:567-74

Asako H, Hiroki $Y$, Ken A, Yoshihide S, Teruo S, Kiichiro M. Characterization of parkin in bovine peripheral nerve. Brain Res 2002;930:143-9

Campos-Ortega JA, Hartenstein V. The embryonic development of Drosophila melanogaster, 1985, Springer-Verlag, Berlin

D' Agata VD, Zhao W, Cavallaro S. Cloning and distribution of the rat parkin mRNA. Mol Brain Res 2000;75:345-9

De Rijk MC, Tzourio C, Breteler MM, Dartigues JF, Amaducci L, Lopez-Pousa S, Manubens-Bertran JM, Alperovitch A, Rocca WA. Prevalence of parkinsonism and Parkinson's disease in Europe: the EUROPARKINSON Collaborative Study. European Community Concerted Action on the Epidemiology of Parkinson's disease. J Neurol Neurosurg Psychiatry 1997;62:10-5

Forno LS. Neuropathology of parkinson's disease. J Neuropathol Exp Neurol 1996;55:259-72

Greene JC, Whitworth AJ, Kuo I, Andrews LA, Feany MB, Pallanck LJ. Mitochondrial pathology and apoptotic muscle degeneration in Drosophila parkin mutants. PNAS 2003; 100:4078-83

Hattori N, Kitada T, Matsumine H, Asakawa S, Yamamura Y, Yoshino H, Kobayashi T, Yokochi M, Wang M, Yoritaka A, Kondo T, Kuzuhara S, Nakamura S, Simizu N, Mizuno $Y$. Molecular genetic analysis of a novel Parkin gene in Japanese families with autosomal recessive juvenile parkinsonism: evidence for variable homozygous deletions in the Parkin gene in affected individuals. Ann Neurol 1998a;44: 935-41

Hattori $\mathrm{N}$, Matsumine $\mathrm{H}$, Asakawa $\mathrm{S}$, Kitada $\mathrm{T}$, Yoshino $\mathrm{H}$, Elibol B, Brookes AJ, Yamamura Y, Kobayashi T, Wang M, Yoritaka A, Minoshima S, Simizu N, Mizuno Y. Point mutations (Thr240Arg and Ala311Stop) in the Parkin gene. Biochem Biophys Res Commun 1998b;249:754-8

Horowitz JM, Myers J, Stachowiak MK, Torres G. Identification and distribution of parkin in rat brain. Neuroreport 1999;10:3393-7

Horowitz JM, Vernace VA, Myers J, Stachowiak MK, Hanlon DW, Fraley GS, Torres G. Immunodetection of Parkin protein in vertebrate and invertebrate brains: a comparative study using specific antibodies. J Chem Neuroanat 2001;21:75-93

Huynh DP, Dy M, Nguyen D, Kiehl TR, Pulst SM. Differential expression and tissue distribution of parkin isoforms during mouse development. Brain Res Dev Brain Res 2001;130:173-81

Imai $\mathrm{Y}$, Soda $\mathrm{M}$, Inoue $\mathrm{H}$. An unfolded putative transmembrane polypeptide, which can lead to endoplasmic reticulum stress, is a substrate of Pakin. Cell 2001;105:891-902

Imai Y, Soda M, Takahashi R. Parkin suppresses unfolded protein stress-induced cell death through its E3 ubiquitinprotein ligase activity. J Biol Chem 2000;275:35661-4

Ishikawa A, Tsuji S. Clinical analysis of 17 patients in 12 Japanese families with autosomal-recessive type juvenile parkinsonism. Neurology 1996;47:160-6

Jang IS, Juhnn YS. Adaptation of CAMP signaling system in SH-SY5Y neuroblastoma cells following expression of a constitutively active stimulatory G protein alpha, Q227L Gsa. Exp Mol Med 2001;33:37-45

Jiang $\mathrm{H}$, Okamura CS, Boyd CK, Lucy MC. Identification of $\mathrm{Sp} 1$ as the transcription factor for the alternative promoter P2 of the bovine growth hormone receptor gene. J Mol Endocrinol 2000;24:203-14

Kitada T, Asakawa S, Hattori N, Matsumine H, Yamamura Y, Minoshima S, Yokochi M, Mizuno Y, Shimizu N. Mutations in the parkin gene cause autosomal recessive juvenile parkinsonism. Nature 1998;392:605-8

Kitada T, Asakawa S, Miinoshima S, Mizuno Y, Shimizu N. Molecular cloning, gene expression and identification of a splicing variant of the mouse Parkin gene. Mamm Genome 2000;11:417-21

Lcking C, Drr A, Bonifati V, Vaugham J, De Michele G, Gasser T, Harhangi BS, Meco G, Denefle P, Wood NW, Agid $Y$, Brice A. Association between early-onset Parkinson's disease and mutations in the parkin gene. French Parkinson's Disease Genetics Study Group. N Engl J Med 2000; 342:1560-7 
Matsumine $H$, Satio M, Shimoda-Matsubayashi S, Tanaka H, Ishikawa A, Hattori $Y$, Yokochi M, Kobayashi T, Igarashi S, Takano H, Sanpei K, Koike R, Mori H, Kondo T, Mizutani Y, Schaffer AA, Yamamura Y, Nakamura S, Kuzuhara S, Tsuji S, Mizuno Y. Localization of a gene for an autosomal recessive form of juvenile parkinsonism to chromosome 6q25.2-27. Am J Hum Genet 1997;60:588-96

Morett E, Bork P. A novel transactivation domain in parkin. Trends Biochem Sci 1999;24:229-31

Mori $\mathrm{H}$, Kondo $\mathrm{T}$, Yokochi $\mathrm{M}$, Matsumine $\mathrm{H}$, NkagawaHattori Y, Miyake T, Suda K, Mizuno Y. Pathologic and biochemical studies of juvenile parkinsonism linked to chromosome 6q. Neurology 1998;51:890-2

Olanow CW, Tatton WG. Etiology and pathogenesis of Parkinson's disease. Annu Rev Neurosci 1999;22:123-44

Polymeropoulos MH, Higgins JJ, Golbe LI, Johnson WG, Ide SE, Di lorio G, Sanges G, Stenroos ES, Pho LT, Schaffer AA, Lazzarini AM, Nussbaum RL, Duvoisin RC. Mapping of a gene for Parkinson's disease to chromosome 4q21-q23. Science 1996;274:1197-9

Polymeropoulos MH, Lavedan C, Leroy E, Ide SE, Dehejia A, Dutra A, Pike B, Root H, Rubenstein J, Boyer R, Stenroos ES, Chandrasekharappa S, Athanassiadou A, Papapetropoulos T, Johnson WG, Lazzarini AM, Duvoisin RC, Di lorio G, Golbe LI, Nussbaum RL. Mutation in the-synuclein gene identified in families with Parkinson's disease. Science 1997;276:2045-7

Quandt K, Frech K, Karas H, Wingender E, Werner T. MatInd and Matlnspector: new fast and versatile tools for detection of consensus matches in nucleotide sequence data. Nucleic Acids Res 1995;23:4878-84

Schenk D, Barbour R, Dunn W, Gordon G, Grajeda H, Guido T, Hu K, Huang J, Johnson-Wood K, Khan K, Kholodenko D, Lee M, Liao Z, Lieberburg I, Motter R, Mutter L, Soriano F, Shopp G, Vasquez N, Vandevert C, Walker S, Wogulis M, Yednock T, Games D, Seubert P. Immunization with amyloid-beta attenuates Alzheimer-disease-like pathology in the PDAPP mouse. Nature 1999:400:173-7
Shimura H, Hattori N, Kubo S, Yoshikawa M, Asakawa S, Minoshima S, Shimizu N, Iwai K, Chiba T, Tanaka K, Suzuki T. Familial Parkinson disease gene product, parkin, is a ubiquitin-protein ligase. Nat Genet 2000;25:302-5

Takahashi H, Ohama E, Suzuki S, Horikawa $Y$, Ishikawa A, Morita T, Tsuji S, Ikuta K. Familial juvenile parkinsonism: clinical and pathological study in a family. Neurology 1994; 44:437-41

West A, Farrer M, Petruceli L, Cookson M, Lockhart P, Hardy $J$. Identification and characterization of the human parkin gene promoter. J Neurochem 2001;78:1146-52

West A, Lockhart P, O'Farell C, Farrer M. Identification of a novel gene linked to parkin via a Bi-directional promoter. J Mol Biol 2003;326:11-9

West A, Maraganore D, Crook J, Lesnick T, Lockhart P, Wilkes K, Kapatos G, Hardy J, Farrer M. Functional association of the parkin gene promoter with idiopathic Parkinson's disease. Hum Mol Genet 2002;11:2787-92

Yamamura Y, Sobue I, Ando K, lida M, Yanagi T, Kondo C. Paralysis agitans of early-onset with marked diurnal fluctuation of symptoms. Neurology 1973;23:239-44

Yang $Y$, Nishimura I, Imai $Y$, Takahashi R, Lu B. Parkin suppresses dopaminergic neuron-selective neurotoxity induced by Pael-R in Drosophila. Neuron 2003;37:911-24

Yun ES, Lee SJ, Kim MJ, Ryu SH, Suh PG. Cloning and characterization of 5'-upstream region of human phospholipase C-b2 gene. Exp Mol Med 2001;33:76-82 